\title{
Validation of analytical algorithms for the estimation of soil thermal properties using de Vries model
}

\author{
Adeniyi M. $\mathrm{O}^{1}$., Oshunsanya S.O. ${ }^{2}$ and E. F. Nymphas ${ }^{3}$ \\ ${ }^{1,3}$ Department of Physics, University of Ibadan, Ibadan, Nigeria \\ ${ }^{2}$ Department of Agronomy, University of Ibadan, Nigeria
}

\begin{abstract}
Soil thermal conductivity, and diffusivity together with the damping depth of soil temperature computed using Amplitude decay, Phase shift, Harmonic (amplitude based and phase based), Arctangent, Logarithmic and conduction-convection algorithms were compared with those obtained from de Vries model. The amplitude decay algorithm yielded the most reliable values of the soil thermal properties of all the estimation methods with mean absolute error (MAE), root mean squared error (RMSE) and relative maximum error (RME) of $0.04,0.05$ and $5.63 \%$ respectively for soil thermal conductivity. Harmonic algorithm (using the amplitude of the first 4 harmonics) gave values of the soil thermal properties next to the amplitude decay algorithm with MAE, RMSE and RME values $0.41,0.44$ and $47.84 \%$ respectively for soil thermal conductivity. Higher error values were associated with the other algorithms. The Arctangent algorithm gave the most deviated values of soil thermal properties with RME of $156.83 \%$ for soil thermal conductivity. For soil moisture content between 0.168 and 0.189 (> critical soil moisture content) the values of the soil thermal properties of the loamy sand decreased with increasing soil moisture, while they increased with increasing soil aeration.
\end{abstract}

Keywords: soil thermal conductivity, soil thermal diffusivity, damping depth, de Vries model, soil moisture content

\section{INTRODUCTION}

Thermal conductivity is the quantity of heat transferred through a unit area of the conducting body such as soil in unit time under a unit temperature gradient. The thermal conductivities of specific soil constituents differ widely. Hence the space-averaged thermal conductivity of a soil depends on its mineral composition and organic matter content as well as the volume composition of water and air (Hillel, 2003). Soil thermal conductivity measurements describe the soil properties which govern the flow of heat through the soil. Soil thermal properties are required in many areas of engineering, agronomy, soil science, hydrology, climatology and geology and in recent years considerable effort have gone into developing techniques to determine these properties, although different methods yield different results (Anandakumar et al., 2001 and Gao et al., 2009). In agriculture, microbial activity, seed germination, seedling emergence and growth, root proliferation, root elongation and root enlargement are influenced by the microclimate which influences thermal properties of soils (Ghuman and Lal, 1985 and Usowicz, 1994). The thermal conductivity of a soil depends on two broad groups of factors; those which are inherent to the soil itself, and those which can be managed or controlled, at least to a certain extent, by human management. Those factors or properties that are inherent to the soil itself include the texture and mineralogical composition of the soil. While those that can be managed externally include soil moisture content and soil management (Ochsner et al., 2001 and Usowicz, 1995). Soil composition is seldom uniform in depth; hence thermal conductivity is generally a function of depth as well as of time. It also varies with temperature, but under normal conditions this variation is ignored. Thermal conductivity is sensitive not only to the mineral composition of a soil but also to the sizes, shapes, and arrangements of soil particles. The conductivity and volumetric heat capacity increase with water content so also the diffusivity. For mineral soils, the thermal diffusivity increases with soil moisture content at low water contents and then gradually decreases with increasing soil moisture contents at high water contents, Farouki (1986). 
Thermal properties of the soil at Nigerian Micrometeorological Experimental (Nimex_3) site Ibadan was found using the data collected on some selected days during the transition period from dry to wet season of the year 2006. The widely used de Vries model was used to estimate soil thermal conductivity from weighted average of experimentally determined conductivities of the various soil constituents. This method has been found reliable yielding conductivity values that are in good agreement with measured values (Ochsner et al., 2001 and Usowics, 1995). Six estimation methods which are; Amplitude decay, phase shift, harmonic (amplitude and phase based), Arctangent, Logarithmic and conduction- convection algorithms were also used to estimate soil thermal diffusivity and conductivity. The different results were then compared with those obtained from de Vries model

This paper aimed at comparing the thermal properties obtained from the estimation algorithms with those obtained from weighted average of measured values to determine the estimation method that yields values of soil thermal properties closest to those obtained from the measured ones.

Climatology of the study area: The Nimex_3 site, where the experiment was conducted is situated at the University of Ibadan, south western Nigeria. The coordinates of the centre of the site is at latitude $7^{\circ}$ $26^{\prime} \mathrm{N}$ and longitude $3^{\circ} 54^{\prime} \mathrm{E}$. The site has an altitude of $200 \mathrm{~m}$ above sea level. The rainfall pattern is bimodal resulting to two main seasons in Nigeria namely wet (April to October) and dry (November to March) which are influenced respectively by two air masses; south-westerlies originating from the Atlantic ocean and north-easterlies that crosses over the Sahara desert. There is a period of "little dry season" (August break) in August during the wet season, Balogun (1981). The period of transition between the dry and wet seasons reveals the distinct signatures of both wet and dry seasons.

\section{MATERIALS AND METHODS}

\section{Measurement techniques}

Meteorological measurements: Measurement of soil temperature at depths 5,10 and $30 \mathrm{~cm}$ in the soil was made using Campbell Scientific thermistor thermocouple that has an accuracy of $\pm 1^{\circ} \mathrm{C}$. Water content reflectometer CS616 made by Campbell scientific was used to measure soil moisture percentage by volume, it has an accuracy of $\pm 3 \%$ of water content. The reflectometer was placed between 0 and $5 \mathrm{~cm}$ depth in the soil. The wind direction was measured by Vector Instruments wind vane W200P with the accuracy of $\pm 2^{0}$ at $14.5 \mathrm{~m}$ height and the wind speed was measured using Vector Instruments cup anemometer A101ML/A100L2) at heights $1 \mathrm{~m}, 3$ $\mathrm{m}, 6 \mathrm{~m}$ and $12 \mathrm{~m}$ with an accuracy of $1 \%$. Data acquisition was done using Campbell Scientific Datalogger CR10X. The experiment was carried out between day of year (DOY)s 52 and 59 of year 2006 it was a transition period from dry to wet season.

Soil sampling and analysis: Six core samples were collected at $0-5 \mathrm{~cm}, 5-10 \mathrm{~cm}$ and $10-30 \mathrm{~cm}$ depths randomly from the study site. These samples were separately used to determine the bulk density following the core method described by Grossman and Reinsch (2002). The mean value of the six samples at each level was used to represent the level while the mean of the eighteen samples was used to represent the site. Soil cores $110 \mathrm{~cm}^{3}$ in volume were used to obtain the samples. The sharp ends of the metal core rings $(5 \mathrm{~cm}$ in diameter and $5 \mathrm{~cm}$ in height) were carefully hammered in a vertical position and ensuring a uniform entry into the soil. Uniform entry of the core into the soil was achieved by placing a thick piece of plank on top of each core. The plank was struck at the center until the core beneath entered completely into the soil. To ensure that samples remained undisturbed, a knife was used to dig out the submerged core and trimmed to its full capacity. The core was emptied into a moisture can and was taken to the laboratory where samples were oven dried at $105^{\circ} \mathrm{C}$ to a constant weight and bulk density was obtained as follows:

$$
\rho_{b}=M_{s} / V_{b}
$$

where $M_{s}=$ Mass of oven-dry soil + cylinder - Mass of cylinder, $V_{b}=$ volume of cylinder and $\rho_{b}=$ bulk density

Total porosity $\left(T_{p}\right)$ was calculated from the parameters of bulk density $\left(\rho_{b}\right)$ and particle density $\left(\rho_{p}\right)$ as shown below:

$$
T_{p}=\left[1-\left(\rho_{b} / \rho_{p}\right)\right] \times 100
$$

where the particle density of an average mineral soil is $2.65 \mathrm{~g} \mathrm{~cm}^{-3}$ (Hillel, 2003) 
Air filled porosity (soil air) $\left(n_{a}\right)$ was calculated as the difference between total porosity and volumetric moisture content (Hillel, 2003) as shown below:

$n_{a}=T_{p}-\theta$

where $\theta=$ volumetric moisture content $\left(\mathrm{cm}^{3} \mathrm{~cm}^{-3}\right)$. Particle size distribution of the soil samples $(<2 \mathrm{~mm})$ was determined using hydrometer method as described by Gee and Or (2002) to ascertain the percentage of sand (quartz), silt and clay content of the soil samples. Field capacity $(F C)$ at $-5 \mathrm{KPa}$ was determined on tension table using the same core samples used for bulk density. Field capacity on volumetric basis was calculated by multiplying the gravimetric moisture content at $\mathrm{FC}$ by the corresponding bulk density using the equation:

$$
F C=\left(\varphi_{F C}\right) \rho_{b}
$$

where $\varphi$ is the gravimetric moisture content (\%), pb is the bulk density at the required depth in $\mathrm{Mg} \mathrm{m}^{-3}$ and FC is field capacity in $\mathrm{cm}^{3} \mathrm{~cm}^{-3}$.

Soil organic matter was determined by loss on ignition (LOI) as described by Cambardella et al. (2001). Air dried soil was oven dried at $105^{\circ} \mathrm{C}$ to a constant weight while $5 \mathrm{~g}$ of the oven dried sample was used for LOI by mass difference after 4 hours in a muffle furnace at $500{ }^{\circ} \mathrm{C}$.

\section{Theoretical background}

1.2.1. Determination of soil thermal conductivity from conductivities of soil constituents using de Vries model (de Vries, 1963)

The soil is considered as a mixture of water, air and solids (combination of different soil minerals and organic matter). Water was assumed to be the continuous fluid for moist and air for dry soil. The thermal conductivity of soil is computed as the weighted average of the conductivities of the various soil constituents as:

$$
\lambda=\frac{\sum_{i=1}^{n} k_{i} \lambda_{i} x_{i}}{\sum_{i=1}^{n} k_{i} x_{i}}
$$

where $n$ is the number of soil constituents

$x_{i}$ is the volume fraction of each constituents and

$\lambda_{i}$ is the thermal conductivity of each constituent

$k_{i}$ are the weighting factors, which depend on the shape and the orientation of the granules of the soil constituents and on the ratio of the conductivities of the constituents.

$k_{o}=1$ and the subsequent $k_{i}$ are computed from:

$$
k_{i}=\frac{1}{3} \sum_{i=1}^{n}\left[1+\left(\frac{\lambda_{i}}{\lambda_{o}}-1\right) g_{i}\right]^{-1}
$$

where $\lambda_{o}=$ conductivity of organic matter

$g_{i}$ represent the shape factors for $i^{\text {th }}$ components granule and

and $g_{1}+g_{2}+g_{3}=1 . \quad g_{1}$ and $g_{2}$ are assumed to be equal so only one shape factor was computed for each constituent.

The value of $g_{1}$ for air-filled pores was computed as equation (7) for moisture content above the critical moisture content. When the moisture content was below the critical moisture content, g1 was computed as equation (8)

$g_{1}=0.333-\frac{n_{a}}{\left(1-v_{s}\right)}(0.333-0.035)$

$g_{1}=0.013+\frac{\theta}{\theta_{c}}\left(g_{1 c}-0.013\right)$

where $\theta c=$ the critical moisture content

$g_{1 c}=$ the value of equation (7) at the critical moisture content.

The measured soil moisture was above the critical water content throughout the period of this investigation, so the air filled pores were assumed to be saturated with water vapour (Ochsner et al., 2001) and the thermal conductivity of the air filled pores was taken to be $\lambda_{c}$ which included $\lambda_{v}$. The thermal conductivity of the air filled pores was also taken to be $\lambda_{a}$ for comparison.

The following measured thermal conductivity values and expression $\left(\mathrm{Wm}^{-1} \mathrm{~K}^{-1}\right)$ were applied in computing the thermal conductivity:

$\lambda_{q}=9.103-0.028 T, \lambda_{m}=2.93, \lambda_{0}=0.251, \lambda_{\mathrm{w}}=$ $0.552+2.34^{*} 10^{-3} T-1.1 * 10^{-5} T^{2}$

$\lambda_{a}=0.0237+0.000064 T, \lambda_{c}=\lambda_{a}+\lambda_{v}, \lambda_{v}=0.074$ 
where the subscripts $q, m, w, a, c, v$ represent, quartz; other soil minerals; water; air, compound of air and vapour and vapour.

The volumetric heat capacity $\left(C_{v}\right)$ for the loamy sand was computed from Campbell and Norman, 1998 as:

$C_{v}=\rho_{s} v_{s} c_{s}+\rho_{w} c_{w} \theta$

where $\rho_{\mathrm{s}}$ is the particle density of the soil solid

$\rho_{w}$ is the density of water

$\mathrm{C}_{\mathrm{w}}$ is the specific heat capacity of water

$\mathrm{C}_{\mathrm{s}}$ is the specific heat capacity of soil solids

\section{Diffusivity from classical heat conduction equation}

Heat flux density in soil is described by Fourier's law as

$$
G=-k \frac{\partial T}{\partial z}
$$

where $k$ is the thermal conductivity of soil, and $d T / d z$ is the temperature gradient.

Equation (1) can be combined with the equation of continuity to give the second order

differential equation which describes temperature as a function of depth and time:

$$
\rho_{s} C_{s} \frac{\partial T}{\partial t}=k \frac{\partial^{2} T}{\partial z^{2}}
$$

Equation (10) describes the heat conduction in one dimension. Here $\rho_{s}$ and $c_{s}$ are the bulk density and specific heat capacity of the soil and $\frac{\partial T}{\partial t}$ is the time rate of change of temperature. If volumetric heat capacity of the soil, $\rho_{s} c_{s}$ is constant with depth, then it can be combined with $k$ to give

$$
\frac{\partial T}{\partial t}=k_{T} \frac{\partial^{2} T}{\partial z^{2}}
$$

where $k_{T}(=\mathrm{k} / \rho \mathrm{pss})$ is the thermal diffusivity of the soil. Equations (10), (11), and (12) form the basis for measurement of soil thermal properties and for prediction of soil temperature once these properties are known. For steady state conditions equation (10) can be used to find $k$ from measurements of soil heat flux $(G)$ and the temperature gradient.

Solution to equation (12) forms the bases for the following algorithms for soil thermal diffusivity With appropriate boundary conditions, solutions to (12) show that soil temperature decreases exponentially with depth and that the phase of the temperature changes with depth as well (Wu and Nofziger, 1999).

\section{Amplitude decay algorithm}

Given the boundary condition:

$\left.T\right|_{z=0}=\bar{T}+A \sin (w t+\phi),(t \geq 0)$

where $T$ is the soil surface temperature

$\bar{T}$ is the mean soil temperature at the surface,

$A$ is the amplitude of the diurnal soil surface temperature wave

$w=2 \pi / P\left(\mathrm{rads}^{-1}\right)$ is the angular velocity of the earth's rotation

$\mathrm{P}=86400 \mathrm{~s}$; the period of the diurnal cycle

$\phi$ is the phase of soil temperature

Soil temperature $T$ at any depth $z$ is given by:

$T(z, t)=\bar{T}+A \exp (w t-z / d+\phi)$

$d=\sqrt{2 k_{T} / w}$ is the damping depth of diurnal temperature wave.

Soil temperature at depth $z=z 1$

$\left.T\right|_{z=z 1}=\bar{T}_{1}+A_{1} \sin \left(w t+\phi_{1}\right),(t \geq 0)$

The amplitude decay algorithm for thermal diffusivity is given by (16)

$k_{T}=\frac{w\left(z_{1}-z_{2}\right)^{2}}{2 \ln \left(A_{1} / A_{2}\right)^{2}}$

\subsubsection{Phase Shift Algorithm}

The phase shift algorithm for thermal diffusivity obtained from equation (13) is given by: 


$$
k_{T}=\frac{\left(z_{1}-z_{2}\right)^{2} w}{2\left(\phi_{1}-\phi_{2}\right)^{2}}
$$

$\phi_{1}$ and $\phi_{2}$ are the initial phases computed from the first harmonics of the soil temperature wave at depths $z_{1}$ and $z_{2}$ respectively.

Logarithmic Algorithm A Fourier series can be used to represent soil surface temperature (equation 13), or soil temperature at any level (equation 14). The Fourier series is given by:

$$
T(z, t)=\bar{T}+\sum_{i=1}^{n}\left[a_{j} \sin (i w t)+b_{j} \cos (i w t)\right]
$$

where $n$ is the number of harmonics and $a_{j}$ and $b_{j}$ are the amplitudes

Setting a boundary condition of $n=2$, the logarithmic algorithm for soil thermal diffusivity is given by equation (19).

Suppose four observations are taken regularly during each day, at 6 hour intervals and at

two different depths, $k_{T}$ can be estimated as (Sellers 1965)

$$
\begin{aligned}
k_{T}= & 4 \pi \frac{\left(d_{2}-d_{1}\right)^{2}}{\tau} \\
& \left\{\ln \frac{\left[T_{1}\left(d_{1}\right)-T_{3}\left(d_{1}\right)\right]^{2}+\left[T_{2}\left(d_{1}\right)-T_{4}\left(d_{1}\right)\right]^{2}}{\left[T_{1}\left(d_{2}\right)-T_{3}\left(d_{2}\right)\right]^{2}+\left[T_{2}\left(d_{2}\right)-T_{4}\left(d_{2}\right)\right]^{2}}\right\}
\end{aligned}
$$

where $d_{1}$ and $d_{2}$ are two different depths, $\mathrm{T}$ is period of daily cycle, i.e., 86400 seconds, $T_{1}, T_{2}, T_{3}$ and $T_{4}$ are temperature measurements at $00,06,12$, and 18 local time, respectively. The e-folding damping depth can then be calculated according to $d=\sqrt{k_{T} \tau / \pi}$.

This method works better for clear sky conditions. Also, to have a better result, $d 1$ and $d 2$

should be separated as far as possible but all within the damping depth $d$. Since daily sinusoidal cannot penetrate beyond $60 \mathrm{~cm}$ for normal soils, it is suggested that the two selected depths should all be limited to within $60 \mathrm{~cm}$ depth. The two selected depth at the Nimex_3 site are $5 \mathrm{~cm}$ and $30 \mathrm{~cm}$ which are within the acceptable limit.

Arctangent Algorithm: The Fourier series in equation (18) can also be used applying the same boundary condition for Logarithmic algorithm to find the thermal diffusivity using Arctangent algorithm given by:

$k_{T}=\frac{w \Delta z^{2}}{2\left\{\arctan \left[\frac{\left(T_{1}\left(d_{1}\right)-T_{3}\left(d_{1}\right)\right)\left(T_{2}\left(d_{2}\right)-T_{4}\left(d_{2}\right)\right)-\left(T_{2}\left(d_{1}\right)-T_{4}\left(d_{1}\right)\right)\left(T_{1}\left(d_{2}\right)-T_{3}\left(d_{2}\right)\right)}{\left(T_{1}\left(d_{1}\right)-T_{3}\left(d_{1}\right)\right)\left(T_{1}\left(d_{2}\right)-T_{3}\left(d_{2}\right)\right)+\left(T_{2}\left(d_{1}\right)-T_{4}\left(d_{1}\right)\right)\left(T_{2}\left(d_{2}\right)-T_{4}\left(d_{2}\right)\right.}\right]\right\}^{2}}$

Harmonic Algorithm: The Fourier series (equation 18) can be extended to harmonic form as:

$T(z, t)=\bar{T}+\sum_{i=1}^{n}\left[A_{i} \sin \left(i w t+\phi_{i}\right)\right]$

where $A_{i}$ is the amplitude of the harmonic $i$

$A_{i}=\sqrt{a_{i}^{2}+b_{i}^{2}}$

The phase, $\phi_{i}=\tan ^{-1}\left(\frac{-a_{i}}{b_{i}}\right)$

Applying the boundary condition:

$\left.T\right|_{z=0}=\bar{T}+\sum_{i=1}^{n}\left[A_{0 i} \sin \left(i w t+\phi_{0 i}\right)\right], \quad(t \geq 0)$

Equation (12) has the solution

$T(z, t)=\bar{T}+\sum_{i=1}^{n}\left[A_{0 i} \exp \left(-z / d_{i}\right) \sin \left(i w t+\phi_{i}-z / d_{i}\right)\right]$

Using equation (24) the amplitude $A_{n i}$ and the initial phase $\phi_{n i}$ at the depth $z_{n}$ can be computed from:

$A_{n i}=A_{(n-1) i} \exp \left(-z / d_{i}\right)$

and

$\phi_{n i}=\phi_{(n-1) i}-z / d_{i}$

Soil temperature rate equation coupled with thermal conductivity and convection: Gao et al. (2003) added a convection term to the classical thermal conduction equation (12)

$\frac{\partial T}{\partial t}=k_{T} \frac{\partial^{2} T}{\partial z^{2}}+W \frac{\partial T}{\partial z}$

Applying the boundary condition:

$\left.T\right|_{z=z_{2}}=\bar{T}_{2}+A_{2} \sin \left(w t+\phi_{2}\right)$

Equation (27) has the solution: 


$$
\begin{gathered}
T\left(z_{1}, t\right)=\bar{T}_{1}+A_{2} \exp \left[-\alpha\left(z_{1}-z_{2}\right) M\right] \\
\sin \left[w t+\phi_{2}-\left(z_{1}-z_{2}\right) \alpha N\right]
\end{gathered}
$$

where

$$
M=\frac{\alpha}{w}\left\{W+\frac{1}{\sqrt{2}}\left[W^{2}+\left(W^{4}+\frac{4 w^{4}}{\alpha^{4}}\right)^{1 / 2}\right]^{1 / 2}\right\}
$$

And

$$
N=\sqrt{2}\left(\frac{w}{\alpha}\right)\left[W^{2}+\left(W^{4}+\frac{4 w^{4}}{\alpha^{4}}\right)^{1 / 2}\right]^{-1 / 2}
$$

$M$ and $N$ are the additional terms in the solution resulting from the incorporation of the convective term. Given the boundary conditions:

$A_{1}=A_{2} \exp \left[-\alpha\left(z_{1}-z_{2}\right) M\right.$

and

$$
\phi_{1}=\phi_{2}+\left(z_{1}-z_{2}\right) \alpha N
$$

Gao (2005) derived $W$ and $k_{T}$ as:

$W=\frac{w\left(z_{1}-z_{2}\right)}{\phi_{1}-\phi_{2}}\left[\frac{2 \ln ^{2}\left(A_{1} / A_{2}\right)}{\left(\phi_{1}-\phi_{2}\right)^{2}+\ln ^{2}\left(A_{1} / A_{2}\right)}-1\right]$

$k_{T}=-\frac{w\left(z_{1}-z_{2}\right)^{2} \ln \left(A_{1} / A_{2}\right)}{\left(\phi_{1}-\phi_{2}\right)\left[\left(\phi_{1}-\phi_{2}\right)^{2}+\ln ^{2}\left(A_{1} / A_{2}\right)\right]}$

The solution to equations (12) and (27) are the same when the soil is dry and the convective term is zero. Then, equations (16) and (17) remain valid.

Validation of various estimation methods: De Vries model was used as the standard measured value since it is known to give reliable values of thermal conductivity compared to measured ones (Uzowics, 1995 and Ochsner et al., 2001. All the methods were compared with de Vries model using the following error analytical methods: mean absolute error (MAE), root mean squared error (RMSE) and relative maximum error (RME).

The MAE is given by:
$M A E=\frac{\sum_{i=1}^{n}\left|y_{i}-\hat{y}_{i}\right|}{n}$

$n=$ number of samples

$y_{i}$ is the standard value and $\hat{y}_{i}$ is the estimated value

The RMSE was computed from:

$R M S E=\sqrt{\frac{\sum_{i=1}^{n}\left(y_{i}-\hat{y}_{i}\right)^{2}}{n}}$

The RME was calculated using:

$R M E=\max _{i=1,2, \ldots, n}\left\{\left|\frac{y_{i}-\hat{y}_{i}}{y_{i}}\right| \cdot 100 \%\right\}$ 


\section{RESULTS AND DISCUSION}

Wind speed and temperature: The wind direction was predominantly northeasterly as expected in this area during the transition period from dry to wet period. Diurnal variation of wind speed and temperature on DOYs $52-58$ on Nimex 3 site is shown in Fig1a and b. Fig 1 revealed that the magnitude of soil temperature and wind speed increased steadily from day to day although the positive slopes were very low.

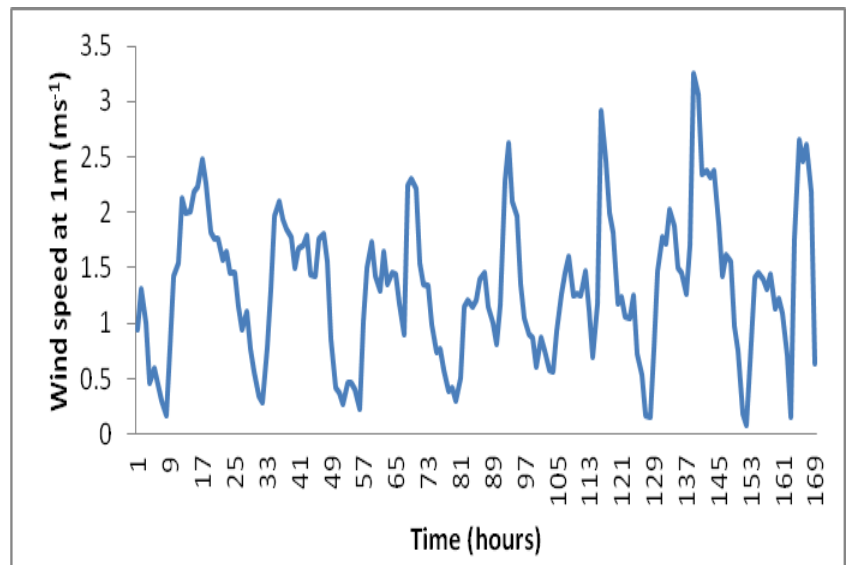

(a)

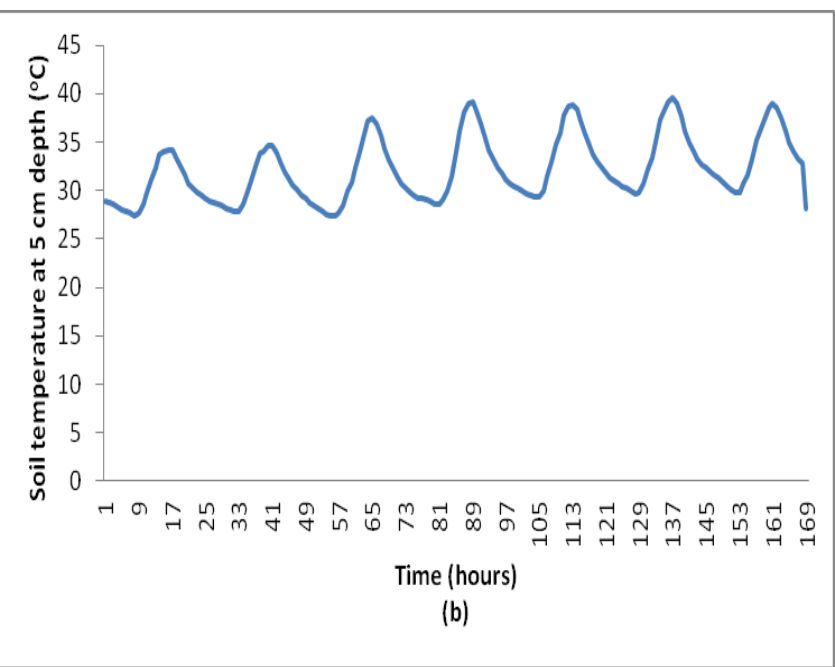

Fig. 1 Variations of (a) wind speed and (b) soil temperature from DOYs 52-58 2006 on Nimex_3 site.

Soil Properties: Analysis of the soil samples obtained from Nimex_3 site showed that particle size distribution respectively for sand, silt and clay content can be grouped into the loamy sand texture (Table 1a), indicating that it is a coarse textured soil characterized with low water retention ability (Hillel, 2003). Soil organic matter value of the site is low resulting to a high bulk density value of $1.56 \mathrm{gcm}^{-3}$ at depth $0-5 \mathrm{~cm}$. The bulk density was higher at deeper depths (Table 1a).

Table 1 a: Soil particle size distribution and physical properties at Nimex_3 site

\begin{tabular}{|l|l|l|l|l|}
\hline $\begin{array}{l}\text { Soil } \\
\text { constituents }\end{array}$ & $\mathbf{0 - 5} \mathbf{c m}$ & $\begin{array}{l}\mathbf{5 - 1 0} \\
\text { cm }\end{array}$ & $\mathbf{1 0 - 3 0}$ cm & Mean \\
\hline Clay & $103.00 \pm 10$ & & $109.00 \pm 19$ & \\
\hline Silt & $71.80 \pm 51.6$ & & $54.67 \pm 23$ & \\
\hline Sand & $825.20 \pm 47$ & & $836.00 \pm 8$ & \\
\hline $\begin{array}{l}\text { Organic } \\
\text { carbon }\end{array}$ & $26.40 \pm 2.4$ & & & \\
\hline $\begin{array}{l}\text { Organic } \\
\text { matter }\end{array}$ & $45.60 \pm 4.1$ & & $38.50 \pm 4$ & 14.53 \\
\hline $\begin{array}{l}\text { Soil physical } \\
\text { properties }\end{array}$ & & 14.52 & 14.92 & 29.03 \\
\hline $\begin{array}{l}\text { Field capacity } \\
(0.05 \text { bar \%) }\end{array}$ & 14.16 & 24.46 & 38.12 & \\
\hline $\begin{array}{l}\text { Hydraulic } \\
\text { conductivity } \\
\text { (cm/hr) }\end{array}$ & 24.50 & 1.60 & 1.79 & 1.65 \\
\hline Bulk density & 1.56 & & \multicolumn{2}{|l|}{} \\
\hline
\end{tabular}

Soil thermal conductivity: Thermal conductivity values obtained from all the methods and their error values as compared to values from de Vries method were presented in Table 1b. De Vries model without vapour resulted into underestimation of the soil thermal conductivity, this is expected since soil moisture was above the critical soil water content throughout the period of this investigation and the air pores should be saturated with water vapour (Ochsner et al., 2001) With the consideration of vapour, the thermal conductivity of the loamy sand increased to about the measured value (about 1.48 $\mathrm{WK}^{-1} \mathrm{~m}^{-1}$ at $\theta / \theta_{\text {sat }}=0.4$ ) Cosby et al., 1984. De Vries model has been found to yield soil conductivity values that are comparable to measured values (Ochsner et al., 2001 and Usowicz, 1995), so it was taken as the standard to which all other methods were compared.

The Amplitude decay method gave estimated conductivity values that were most comparable to those obtained from de Vries model (with vapour) with very small bias, MAE, RMSE and RME, Table 
1b. The amplitude method has been shown to give thermal conductivity values that are very close to the measured ones, Adams et al. (1976). Thermal conductivity values obtained from phase shift method almost doubled those from de Vries method and the error values were high, Table1b.The Harmonic method based on phase shift presented the same thermal conductivity and error values as the phase shift method. The harmonic method of amplitude also gave thermal conductivity values that are far from the measured ones when the amplitudes of the first harmonic alone were used. With the combination of four harmonics giving above $90 \%$ of the whole amplitude, the thermal conductivity and the error values reduced making the estimated values to be closer to the measured ones. Thermal conductivity obtained from the conduction-convection and Logarithmic methods were similar and they were higher than the measured ones but not as high as those from the Arctangent method. The method with the highest relative maximum error was Arctangent and the least errors were found in conductivity values obtained from Amplitude decay method, de Vries method with no vapour yielded values with more errors than Amplitude decay method, Table 1b.

The critical soil water content at Nimex_3 site between 0 and $5 \mathrm{~cm}$ was $14.16 \%$ which was less than the soil water content during this investigation. Soil thermal conductivity increases with soil moisture at low soil moisture content but the increment stops at the critical soil water content (Salomone and Marlowe, 1989). The soil water content during this investigation ranged between 16 and 19\% evaluation of the variation of soil thermal conductivity with soil water and air water content revealed an inverse relationship with soil water content and direct relationship with soil

air content during the period of investigation (Figs 2 and 3).

Table 1b Soil thermal conductivity computed from various models

\begin{tabular}{|l|l|l|l|l|l|l|l|l|}
\hline $\begin{array}{l}\text { DeVries } \\
\text { With } \\
\text { Vapor }\end{array}$ & $\begin{array}{l}\text { Amplitu } \\
\text { de } \\
\text { decay }\end{array}$ & $\begin{array}{l}\text { Phase } \\
\text { Shift }\end{array}$ & Arctan & Logari & $\begin{array}{l}\text { Cond- } \\
\text { conv }\end{array}$ & Ampli & $\begin{array}{l}\text { Harmonic } \\
\text { phase }\end{array}$ & ampl(4 \\
\hline 1.433 & 1.460 & 2.141 & 1.939 & 2.464 & 1.808 & 2.080 & 2.080 & 1.740 \\
\hline 1.434 & 1.449 & 2.373 & 2.202 & 2.187 & 1.983 & 2.060 & 2.320 & 1.690 \\
\hline 1.434 & 1.485 & 3.071 & 3.683 & 1.861 & 2.442 & 2.090 & 3.020 & 2.120 \\
\hline 1.435 & 1.503 & 3.081 & 3.231 & 2.139 & 2.384 & 2.170 & 3.000 & 2.020 \\
\hline 1.436 & 1.503 & 2.680 & 2.729 & 2.119 & 2.151 & 2.210 & 2.680 & 1.980 \\
\hline 1.437 & 1.436 & 2.516 & 2.792 & 2.108 & 2.065 & 2.120 & 2.530 & 1.830 \\
\hline 1.439 & 1.358 & 2.209 & 2.103 & 2.054 & 1.877 & 2.040 & 2.230 & 1.670 \\
\hline 1.440 & 1.408 & 2.255 & 2.273 & 1.994 & 1.880 & 2.020 & 2.290 & 1.730 \\
\hline MAE & 0.043 & 1.099 & 1.183 & 0.680 & 0.638 & 0.663 & 1.083 & 0.412 \\
\hline RMSE & 0.050 & 1.148 & 1.312 & 0.670 & 0.675 & 0.666 & 1.132 & 0.442 \\
\hline RME(\%) & 5.63 & 114.16 & 156.83 & 72.23 & 70.29 & 53.90 & 110.60 & 47.84 \\
\hline
\end{tabular}

Soil Thermal Diffusivity: The soil thermal diffusivity values obtained from de Vries model with vapour was used as the standard values. The performance of the various methods in the estimation of soil thermal diffusivity is the same as in estimating soil thermal conductivity. The Arctangent method yielded the most deviated values from the measured followed by the phase shift and Harmonic (phase). Lower error values were found in estimated values from logarithmic, harmonic (amplitude) and conductionconvection methods. The lowest errors were found in
The Amplitude decay estimated values. The improved Harmonic (amplitude) method also yielded values that were closer to the measured ones than the other methods, Table 2.

Variations of soil thermal diffusivity with soil water content and air water content were similar to those of soil thermal conductivity with them (Figs. 2 and 3), Ochsner et al., 2001. Soil thermal diffusivity decreased with soil water content but increases with soil air content at soil water content $>\theta_{\mathrm{fc}}$. Farouki (1986). 
Am. J. Sci. Ind. Res., 2012, 3(2): 103-114

Table 2 Soil thermal diffusivity computed from various models

\begin{tabular}{|l|l|l|l|l|l|l|l|l|}
\hline $\begin{array}{l}\text { DeVries } \\
\text { With } \\
\text { Vapor }\end{array}$ & $\begin{array}{l}\text { Amplitu } \\
\text { de } \\
\text { decay }\end{array}$ & $\begin{array}{l}\text { Phase } \\
\text { shift }\end{array}$ & Arctan & Logari & $\begin{array}{l}\text { Cond- } \\
\text { conv }\end{array}$ & Ampli & $\begin{array}{l}\text { Harmonic } \\
\text { phase }\end{array}$ & ampl(4 \\
\hline 0.753 & 0.768 & 1.127 & 1.020 & 1.300 & 0.951 & 1.120 & 1.130 & 0.940 \\
\hline 0.759 & 0.766 & 1.260 & 1.160 & 1.160 & 1.049 & 1.110 & 1.260 & 0.910 \\
\hline 0.764 & 0.790 & 1.630 & 1.960 & 0.990 & 1.299 & 1.130 & 1.630 & 1.150 \\
\hline 0.770 & 0.808 & 1.620 & 1.740 & 1.150 & 1.282 & 1.170 & 1.620 & 1.090 \\
\hline 0.776 & 0.812 & 1.450 & 1.470 & 1.150 & 1.163 & 1.190 & 1.450 & 1.070 \\
\hline 0.782 & 0.780 & 1.370 & 1.520 & 1.150 & 1.220 & 1.150 & 1.370 & 0.990 \\
\hline 0.788 & 0.742 & 1.210 & 1.150 & 1.120 & 1.026 & 1.110 & 1.210 & 0.910 \\
\hline 0.792 & 0.774 & 1.240 & 1.250 & 1.100 & 1.033 & 1.090 & 1.240 & 0.930 \\
\hline MAE & 0.024 & 0.590 & 0.636 & 0.367 & 0.355 & 0.361 & 0.591 & 0.226 \\
\hline RMSE & 0.028 & 0.617 & 0.704 & 0.377 & 0.376 & 0.362 & 0.617 & 0.243 \\
\hline RME(\%) & 5.84 & 113.35 & 156.54 & 72.64 & 70.03 & 53.35 & 113.35 & 50.52 \\
\hline
\end{tabular}

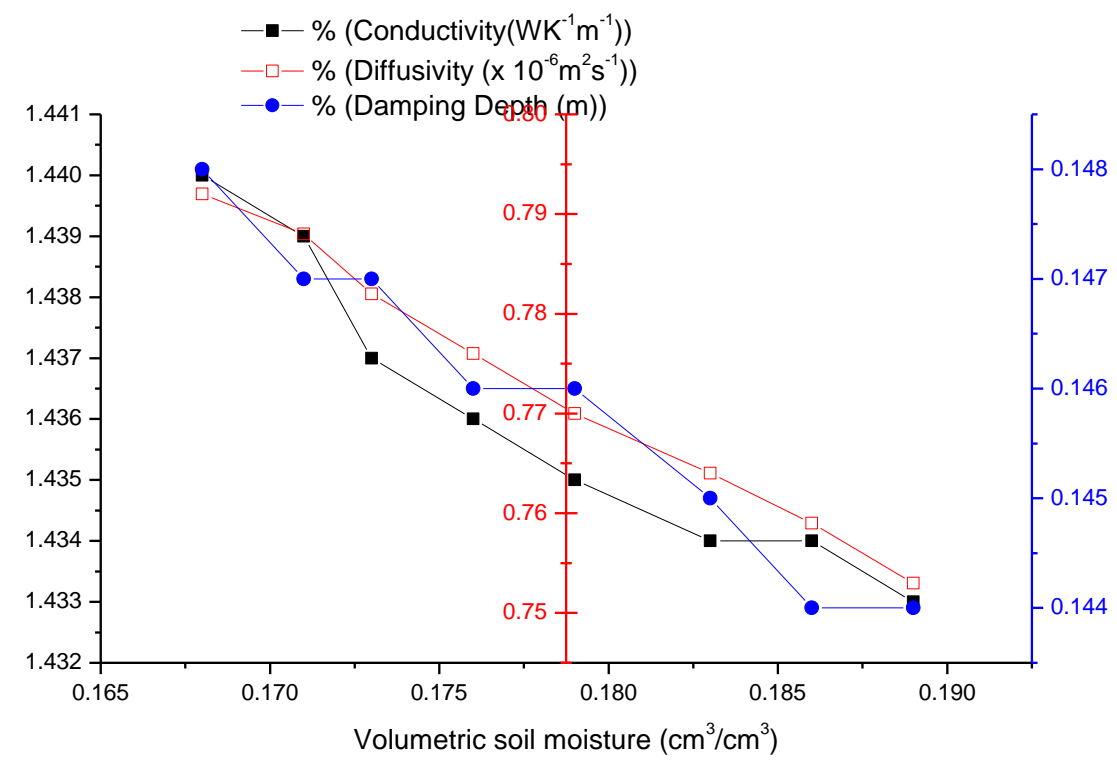

Figure 2: Variations of soil thermal conductivity and diffusivity and damping depth of soil temperature with soil moisture at Nimex_3 site, Ibadan. 
Am. J. Sci. Ind. Res., 2012, 3(2): 103-114

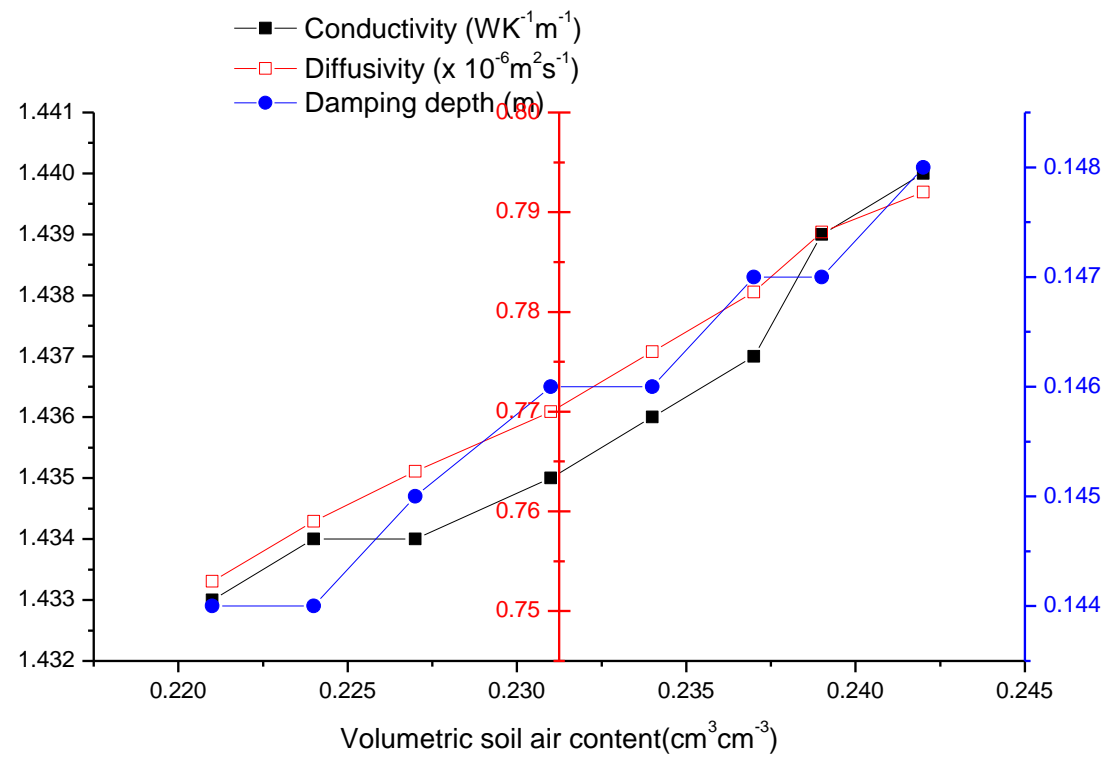

Figure 3: Variations of soil thermal conductivity and diffusivity and damping depth of soil temperature with soil air at Nimex_3 site, Ibadan.

soil water content and vice versa for soil air content (Table3, Figs 2 and 3).

Damping depth of soil temperature: The variation of damping depth with soil water and air water content is similar to those of soil thermal conductivity and thermal diffusivity. It decreases with increasing

Table 3: Damping depth of soil temperature computed from various models

\begin{tabular}{|l|l|l|l|l|l|l|l|l|}
\hline $\begin{array}{l}\text { DeVries } \\
\text { With } \\
\text { Vapor }\end{array}$ & $\begin{array}{l}\text { Amplitu } \\
\text { de } \\
\text { decay }\end{array}$ & $\begin{array}{l}\text { Phase } \\
\text { shift }\end{array}$ & Arctan & Logari & $\begin{array}{l}\text { Cond- } \\
\text { conv }\end{array}$ & Ampli & $\begin{array}{l}\text { Harmonic } \\
\text { phase }\end{array}$ & ampl(4 \\
\hline 0.144 & 0.145 & 0.176 & 0.168 & 0.189 & 0.162 & 0.176 & 0.176 & 0.161 \\
\hline 0.144 & 0.145 & 0.186 & 0.179 & 0.178 & 0.170 & 0.175 & 0.186 & 0.158 \\
\hline 0.145 & 0.147 & 0.212 & 0.232 & 0.165 & 0.189 & 0.176 & 0.211 & 0.178 \\
\hline 0.146 & 0.149 & 0.211 & 0.219 & 0.178 & 0.188 & 0.179 & 0.211 & 0.173 \\
\hline 0.146 & 0.149 & 0.200 & 0.201 & 0.177 & 0.179 & 0.181 & 0.200 & 0.172 \\
\hline 0.147 & 0.146 & 0.194 & 0.204 & 0.177 & 0.176 & 0.178 & 0.194 & 0.165 \\
\hline 0.147 & 0.143 & 0.182 & 0.178 & 0.176 & 0.168 & 0.174 & 0.182 & 0.158 \\
\hline 0.148 & 0.146 & 0.185 & 0.185 & 0.174 & 0.169 & 0.173 & 0.185 & 0.160 \\
\hline MAE & 0.002 & 0.047 & 0.050 & 0.031 & 0.029 & 0.031 & 0.047 & 0.020 \\
\hline RMSE & 0.002 & 0.049 & 0.054 & 0.032 & 0.031 & 0.031 & 0.049 & 0.021 \\
\hline RME(\%) & 2.06 & 46.21 & 38.78 & 23.61 & 30.34 & 23.97 & 46.21 & 22.76 \\
\hline
\end{tabular}

Daily variations of soil thermal properties: The soil thermal conductivity, diffusivity and damping depth of soil temperature have similar variation, they increased from day to day as the soil water content decreases and soil temperature and wind speed increases during the period of this investigation, (Figs 1 and 4). 
Am. J. Sci. Ind. Res., 2012, 3(2): 103-114

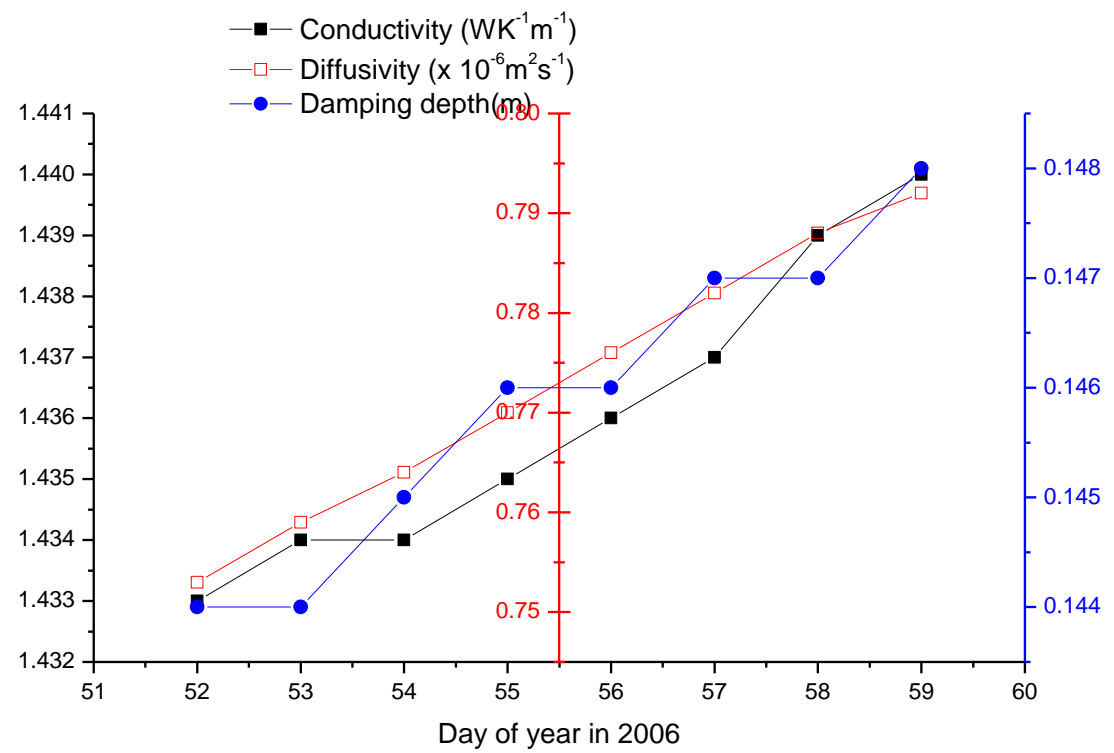

Figure 4 Daily variations of soil thermal conductivity and diffusivity and damping depth of soil temperature at Nimex_3 site, Ibadan

Conclusion: De Vries model with vapour gave values of soil thermal conductivity, diffusivity that were comparable with the measured ones. Of all the estimation algorithms the amplitude algorithm gave the best estimates of the soil thermal properties, the harmonic algorithm with the consideration of amplitude decay also gave a good estimate. All the other methods have more associated errors. The simple amplitude decay method was the best estimation method considered, Adams et al. (1976).

\section{ACKNOWLEDGEMENT}

The Authors acknowledge the efforts of all the partakers of the Nigerian Micrometeorological Experiment. The effort of the laboratory technologist that analyzed the soil is greatly appreciated.

\section{REFERENCES}

Adams, W. M., Watts, G and Mason, G (1976). Estimation of thermal diffusivity from field observations of temperature as a function of time and depth. American Mineralogist 61: 560-568

Anandakuma, K., Venkatesan, R and Prabia, T.V (2001). Soil thermal properties at Kalpakkam in coaster south India. Proceedings of the Indian Academy of Science 110(3): 239-245

Balogun, E. E (1981). Seasonal and spatial variations in thunderstorm activity over Nigeria. Weather 36: 192197
Cambardella, C. A., Gajda, A.M., Doran, J. W., Wienhold, B. J and Kettler, T. A (2001). Estimation of Particulate and Total Organic Matter by Weight Loss-on-ignition. In: Assessment Methods for Soil Carbon, Lal R, Kimble RMJ, Follett RJ, Stewart BA (Eds.) Lewis Publishers, CRC Press, Boca Raton, FI., pp: 349-359

Campbell, G. S and Norman, J. M (1998). An introduction to environmental biophysics $2^{\text {nd }}$ ed. Springer- Verlag, New York 286 pp

Cosby, B. J., Hornberger, G. M., Clapp, R. A and Ginn, T. R (1984). A statistical exploration of the relationships of soil moisture characteristics to the physical properties of the soils. Water Resour Res 20: 682-690

De Vries, D. A (1963). Thermal Properties of Soils. In van Wijk WR (eds.) Physics of Plant Environment. NorthHolland Publishing Company, Amsterdam pp 210-235

Farouki, O. T (1986). Thermal Properties of Soils. Series on rock and soil mechanics. Vol. 11. Trans Tech Publ, Clausthal-Zellerfeld, Germany 136 pp

Flint, L. E and Flint, A. L. 2002. Porosity. In: J. H. Dane and G. C. Topp (eds.) Methods of soil analysis. Part 4, Physical Methods, SSSA, Incorporated, Madison, 241 $-254$.

Gao, Z., Wang, L and Horton, R (2009). Comparison of six algorithms to determine the soil thermal diffusivity at a site in the Loess Plateau of China. Hydrol Earth Syst Sci Discuss 6: 2247-2274. 
Gao, Z., Fan, X and Bian, L (2003) An analytical solution to one dimensional thermal conduction-convection in soil. Soil Science 168(2): 99-107

Gao, Z (2005). Determination of soil heat flux in a Tibetan short grass praire. Boundary- Layer Meteorology 114: $165-178$

Gee, G. W and Or, D (2002). Particle size analysis. In: Dane JH, Topp GC (eds.) Methods of soil analysis. Part 4, Physical Methods, SSSA, Incorporated, Madison, 255 - 294.

Ghuman, B. S, Lal, R (1985) Thermal conductivity, thermal diffusivity, and thermal capacity of some Nigerian soils. Soil Science 139: 74-80

Grossman, R. B, and Reinsch, T. G (2002) Bulk density and linear extensibility: Core method. In: Dane J. $\mathrm{H}$ and Topp G. C (eds.) Methods of soil analysis. Part 4, Physical Methods, SSSA, Incorporated, Madison, 208 $-228$.
Hillel, D (2003). Introduction to environmental soil physics. Academic Press Limited, London, 484 pp

Ochsner, T. E, Horton R and Ren T (2001). A new perspective on soil thermal properties. Soil Sci Soc Am J 65: 1641-1647

Salomone, L. A and Marlow, J. I (1989). Soil rock classification according to thermal conductivity EPRICU-6482, Electric Power Research Institute Palo Alto, CA.

Seeman, J (1979). Measurement technology, Agrometeorology, Springer-Verlag, Berlin, 40-45.

Usowicz, B (1994). Control of thermal and moisture regime in soil. Int. Agrophysics 8: 155-160.

Wu J, Nofziger, D. L (1999). Incorporating temperature effects on pesticide degradation into a management model. J Environ Qual 28:92-100 